Supporting Information

\title{
Codelivery Nanosystem Targeting the Deep Microenvironment of Pancreatic Cancer
}

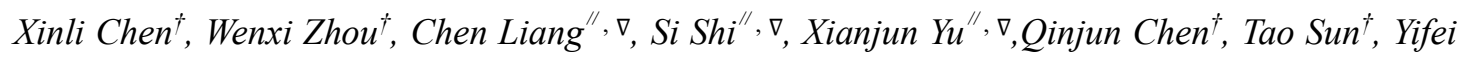

Lù $^{\dagger}$, Yujie Zhang', Qin Guo ${ }^{\dagger}$, Chao Lì, Yu Zhang ${ }^{\dagger}$, ,Chen Jiang ${ }^{\dagger *}$

$\dagger$ Key Laboratory of Smart Drug Delivery

Ministry of Education

State Key Laboratory of Medical Neurobiology

Research Center on Aging and Medicine

Department of Pharmaceutics

School of Pharmacy

Fudan University

Shanghai 201203, China

E-mail: jiangchen@shmu.edu.cn

"Department of Pancreatic and Hepatobiliary Surgery,

Fudan University Shanghai Cancer Center,

270 Dongan Road,

Shanghai 200032, China

$\nabla$ Department of Oncology,

Shanghai Medical College,

Fudan University,

Shanghai 200032, China 


\section{Experimental section}

Materials. uPAR targeting peptide AE105 (C-D-Cha-F-s-r-Y-L-W-S) was purchased from Chinapeptide (Shanghai, China). $\alpha$-Methoxy- $\omega$-amino-poly (ethylene glycol) (mPEG-NH $2, \mathrm{MW}$ $5000)$ and maleimide- $\omega$-amino-poly(ethylene glycol) (Mal-PEG-NH $\left.\mathrm{NH}_{2}, \mathrm{MW} 5000\right)$ were purchased from Jenkem Biotech (Beijing, China). 4-(Dimethylamino) pyridine, N, NDicyclohexylcarbodiimide, 3, 5-dimethyl-1-pyrazolylformamidinium nitrate, Lysine-Ncarboxyanhydride and Boc-L-ornithine were purchased from Aladdin Chemistry (Shanghai, China). Triphosgene was purchased from Tokyo Chemical Industry (Shanghai, China). BODIPY-NHS (Ex/Em : 650/665) were purchased from Molecular Probes (ThermoFisher, USA). Paclitaxel (MB1178), gemcitabine (MB1113) and D-Luciferin potassium (MB1834) were purchased from Dalian Meilun Biotechnology Co., Ltd (Dalian, China). Phosphorylated gemcitabine was a gift from Dr. Qingbing Wang (Ruijin Hospital, Shanghai, China). 3-(4, 5-dimethyl-2-thiazolyl)-2, 5-diphenyl2H tetrazolium bromide (MTT) was purchased from Sigma-Aldrich (St. Louis, USA). Antibodies against cell surface markers for flow cytometry (fluorescent-activated cell sorting) assay were purchased from eBioscience (CA, USA) and Abcam (Cambrige, England). One step TdT-mediated dUTP Nick-End Labeling (TUNEL) apoptosis assay kit and annexin V-FITC/PI apoptosis detection kit were purchased from KeyGEN BioTECH (Nanjing, China). Other reagents without specified explanation were purchased from Sinopharm Chemical Reagent (Shanghai, China).

Cells lines. MiaPaCa-2 cells, purchased from American Type Culture Collection (ATCC), highly metastatic human pancreatic cancer epithelial cell, are applied for the construction of pancreatic ductal adenocarcinoma model in nude mice. PANC02-luci cells are gift from Prof. Zhigang Zhang 
at Shanghai Cancer Institute. It was used for the manufacture of mouse pancreatic ductal cancer model in the C57BL/6 mice. MiaPaCa-2 and PANC-02 cells were carefully maintained in high glucose DMEM medium supplemented with $10 \%$ heat-inactivated FBS and $10 \mathrm{mM}$ 4-(2hydroxyethyl)-1-piperazineethanesulfonic acid (HEPES), $100 \mathrm{U} / \mathrm{mL}$ penicillin and $100 \mu \mathrm{g} / \mathrm{mL}$ streptomycin at $37^{\circ} \mathrm{C}$ and $5 \% \mathrm{CO}_{2}$.

Preparation of HSA-PTX. HSA-PTX nanoparticle was prepared according to previous precedures. ${ }^{1-2}$ Briefly, $20 \mathrm{mg}$ of PTX dissolved in $20 \mathrm{~mL}$ of ethanol was added into $1 \mathrm{~mL}$ HSA solution $(20 \mathrm{mg} / \mathrm{mL})$ drop-wisely. The suspension was stirred at room temperature for $30 \mathrm{~min}$ and sonicated for $5 \mathrm{~min}$. Then, the mixture was dialyzed (MWCO: $12-14 \mathrm{kDa}$ ) overnight to remove residual free PTX and ethanol.

Synthesis of Orn-(Boc)-NCA. Boc-L-ornithine NCA was synthesized according to previous procedures. ${ }^{3}$ Briefly, boc-L-ornithine $(1 \mathrm{~g}, 4.31 \mathrm{mmol})$ was added to flask with anhydrous tetrahydrofuran (THF, $34.3 \mathrm{~mL})$. A solution of triphosgene $(0.47 \mathrm{~g}, 1.6 \mathrm{mmol})$ in anhydrous THF $(6.9$ $\mathrm{mL}$ ) was added to the slurry. The mixture was heated to $50^{\circ} \mathrm{C}$ for $1 \mathrm{~h}$ before cooled to ambient temperature. The insoluble solid was removed by filtration washing with $10 \mathrm{~mL}$ anhydrous THF. The filtrate was concentrated by vacuum distillation to $10 \mathrm{ml}$ and the solvent was switched to n-hexane $(10 \mathrm{~mL})$. The resulting slurry was filtrated and dried to give a white crystalline product.

Synthesis of Lys-(Cbz)-NCA. Lysine-N-Carboxyanhydride were synthesized according to previous procedures. ${ }^{4}$ Briefly, lysine-N-Carboxyanhydride $(3 \mathrm{~g}, 10.7 \mathrm{mmol})$ and triphosgene $(1.27 \mathrm{~g}, 4.28$ 
mmol) was added to flask with anhydrous THF $(30 \mathrm{~mL})$. The mixture was heated to $50^{\circ} \mathrm{C}$ for $3 \mathrm{~h}$ until the solution become clear. The insoluble solid was removed by filtration. The filtrate was added to the cooled n-hexane. The resulting slurry was filtrated and dried to give a white crystalline product.

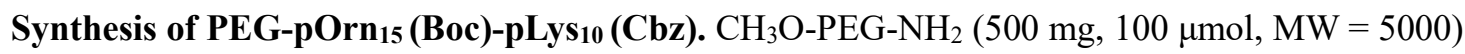
and Orn-(Boc)-NCA (390 mg, $1.5 \mathrm{mmol})$ were mixed in the $5 \mathrm{~mL}$ DMF and reacted at $50{ }^{\circ} \mathrm{C}$ under nitrogen. After $48 \mathrm{~h}$, Lys-(Cbz)-NCA (306 mg, $1.0 \mathrm{mmol})$ in $5 \mathrm{~mL}$ DMF was added to the reaction mixture, and the reaction was maintained for another $48 \mathrm{~h}$. The unreacted materials were removed by dialysis for $24 \mathrm{~h}$, followed by freeze-drying.

Synthesis of PEG-pOrn 15-pLys 10 (Cbz): PEG-pOrn 15 (Boc)-pLys 10 (Cbz) (600 mg, $52 \mu \mathrm{mol})$ was dissolved in dichloromethane (35 mg/mL polymer). Trifluoroacetic acid was added to the solution (1:1 dichloromethane:trifluoroacetic acid by volume). The reaction continued for $20 \mathrm{~min}$ at room temperature. The deprotected polymer was obtained by dialysis in deionized water for $48 \mathrm{~h}$ and lyophilization.

Synthesis of AE105-PEG-pOrn(Boc) ${ }_{15}$-pLys(CBZ)10. AE105 peptide $(152 \mathrm{mg}, 110 \mu \mathrm{mol})$ and Mal-PEG-pOrn(Boc) ${ }_{15}$-pLys(CBZ) ${ }_{10}(1.14 \mathrm{~g}, 100 \mu \mathrm{M})$ were mixed in the $5 \mathrm{~mL}$ anhydrous dimethyl formamide (DMF) and reacted for $2 \mathrm{~h}$ at room temperature. The unreacted materials were removed by dialysis $(\mathrm{MW}=3500)$ for $24 \mathrm{~h}$, followed by freeze-drying.

Synthesis of PEG-pArg ${ }_{15}-$ Lys $_{10}$ (Cbz). PEG-pArg ${ }_{15}-$ pLys $_{10}$ (Cbz) was prepared by the 
guanidization of the obtained PEG-pOrn ${ }_{15}$-pLys10 (Cbz) with 3,5-dimethyl-1pyrazolylformamidinium nitrate. PEG-pOrn ${ }_{15}$-pLys $_{10}(\mathrm{Cbz})(500 \mathrm{mg}, 50 \mu \mathrm{mol})$ and 3,5-dimethyl-1pyrazolylformamidinium nitrate $(262 \mathrm{mg}, 1.3 \mathrm{mmol})$ were dissolved in $15 \mathrm{~mL}$ deionized water, then the $\mathrm{pH}$ of the solution was adjusted to 9.3 with $1 \mathrm{M}$ sodium hydroxide. The mixture was reacted at $37^{\circ} \mathrm{C}$ for $48 \mathrm{~h}$, and then dialyzed against deionized water for another $48 \mathrm{~h}$. The solution was freezedried to get the PEG-pArg 15 -pLys 10 (Cbz) in white powder.

Synthesis of PEG-pArg 15 -pLys 10 . The deprotected of PEG-pArg 15 -pLys 10 (Cbz) was performed by adding the polymer $(500 \mathrm{mg}, 47 \mu \mathrm{mol})$ with TFA $(5 \mathrm{~mL})$ and $\mathrm{HBr} / \mathrm{HOAc}(0.25 \mathrm{~mL})$ to remove the Cbz groups. The reaction continued for $0.5 \mathrm{~h}$ followed by dialysis in deionized water and freezedrying.

Synthesis of 2-propionic-3-methylmaleic anhydride (CDM). Sodium hydride (164 mg, 6.84 mmol) and triethyl-2-phosphonopropionate $(2.02 \mathrm{~g}, 8.48 \mathrm{mmol})$ were added sequentially to $14 \mathrm{~mL}$ of anhydrous THF on ice. The suspension was stirred on ice until the completion of hydrogen gas generation. Dimethyl-2-oxoglurate $(1.00 \mathrm{~g}, 5.71 \mathrm{mmol})$ was added and stirred for $30 \mathrm{~min}$. Then, 21 $\mathrm{mL}$ of saturated ammonium chloride aqueous solution was added, followed by extraction with diethyl ether. Following solvent evaporation, the crude product was purified by silica gel column chromatography (diethyl ether/n-hexane $=2 / 1, \mathrm{Rf}=0.6$ ). The obtained yellow-colored oil was dissolved in $25 \mathrm{~mL}$ of ethanol and mixed with $15 \mathrm{~mL}$ of $2 \mathrm{M}$ sodium hydroxide solution. The mixture was refluxed for $1 \mathrm{~h}$ and cooled to room temperature. Ethanol was removed by evaporation. $1 \mathrm{M}$ hydrochloric acid was added to adjust the $\mathrm{pH}$ to 2 , followed by extraction with ethyl acetate. CDM 
was collected by recrystallization from the mixture of THF and n-hexane as white crystals.

Synthesis of PTX-CDM. DCC (37.5 mg, $0.182 \mathrm{mmol})$ was dissolved in $200 \mu \mathrm{L}$ of DMF, and CDM (30.5 mg, $0.166 \mathrm{mmol}$ ) was dissolved in $100 \mu \mathrm{L}$ of DMF. Both solutions were mixed together and cooled for $20 \mathrm{~min}$ to $-18^{\circ} \mathrm{C}$. Then, a solution of PTX (100 mg, $\left.0.117 \mathrm{mmol}\right)$ and DMAP (14 mg, $0.117 \mathrm{mmol}$ ) in $300 \mu \mathrm{L}$ of DMF was added. The reaction proceeded at $4^{\circ} \mathrm{C}$ for $20 \mathrm{~h}$. The product was purified by silica gel column (ethyl acetate:hexane $=2: 1$ ).

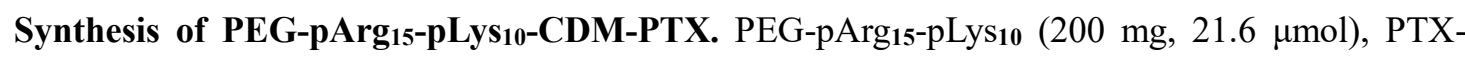
CDM (110 mg, $107.8 \mu \mathrm{mol}$ ) and N, N-Diisopropylethylamine (DIPEA, $107.8 \mu \mathrm{mol})$ were dissolved in $5 \mathrm{~mL}$ DMF. The solution was stirred for $12 \mathrm{~h}$ at room temperature. The product was dialyzed against DMF for $24 \mathrm{~h}$ and deionized water for 24 hours followed by freeze-drying.

Preparation and characterization of micelles. Different ratios of PEG-pOrn ${ }_{15}-\mathrm{pLys}_{10}-\mathrm{PTX}_{4}(\mathrm{RKP})$ and AE105-PEG-pOrn 15 -pLys 10 -PTX 4 (T-RKP) were dissolved in DMF $(10 \mathrm{mg} / \mathrm{mL})$ then sealed in a dialysis bag $($ diameter $=18 \mathrm{~mm}, \mathrm{MWCO}=5000)$. Upon a true solution was formed, the mixture was dialyzed in PBS $(\mathrm{pH}=8.0)$ for $12 \mathrm{~h}$ and to obtain RKP and T-RKP micelle solution with obvious opalescence. $5 \mathrm{mg}$ of phosphorylated gemcitabine (p-GEM) was added into the micelle and vibrated for $2 \mathrm{~min}$. The unbound phosphorylated gemcitabine by dialysis in PBS $(\mathrm{pH}=8.0)$ for $12 \mathrm{~h}$. Micelles for TEM and DLS were filtered through a $0.22 \mu \mathrm{m}$ cellulose acetate filter. Size and PDI of the freshly prepared micelles were measured by dynamic light scattering (DLS) (Zetasizer Nano-ZS, Malvern, U.K.). The morphology of the micelles were photographed by transmission electron microscope 
(TEM, Tecnai G2 spirit Biotwin, FEI).

pH-sensitive drug release of the micelles. HPLC was used to evaluate the drug release. The trigger was set with PBS of $\mathrm{pH} 6.5$ or 7.4 at $37^{\circ} \mathrm{C} .300 \mu \mathrm{L}$ freshly prepared T-RKP micellar solution was sealed into a dialysis bag $(\mathrm{MWCO}=2000)$ against $25 \mathrm{~mL} \mathrm{0.1 \%} \mathrm{Tween-80} \mathrm{containing} \mathrm{PBS} \mathrm{buffer.}$ The PTX or p-GEM release was monitored by HPLC and measured in triplicate at certain time points during $24 \mathrm{~h}$.

Cellular uptake. MiaPaCa-2 cells were seeded with a density of $1 \times 10^{5}$ per well in 6 well plates, incubated at $37^{\circ} \mathrm{C}$ for $72 \mathrm{~h}$, and monitored under microscope until with a $80 \sim 90 \%$ confluency and similar morphology. The cells were then cultured with BODIPY labelled RKP with different percentage of AE105 $(0,10,20,40$ and $80 \%)$ in the DMEM medium at $37{ }^{\circ} \mathrm{C}$ for $2 \mathrm{~h}$. The unbound micelles were washed thrice with D-glucose-free Hank's, visualized by fluoresce microscope (Leica, Wetzlar, Germany).

Biodistribution study in vivo and ex vivo. Targeting study was carried out on tumor-bearing nude mice 10 days post implantation with pancreatic tumor. T-RKP and RKP $(5 \mathrm{mg} / \mathrm{kg}$ of BODIPY) were intravenously injected into the tumor-bearing mice. The in vivo biodistribution of micelles at various time points was traced and visualized by Xenogen IVIS spectrum CT (Perkin Elmer Inc., Waltham, Massachusetts, USA). For the section observation, the mice were anaesthetized, perfused with $4 \%$ (v/v) paraformaldehyde aqueous solution and executed by the decapitation method. The tumor sections were excised, immersed in $4 \%(\mathrm{v} / \mathrm{v})$ paraformaldehyde aqueous solution $(12 \mathrm{~h})$, and 
embedded in the OCT medium (Sakura, Torrance, CA, USA) at $-80^{\circ} \mathrm{C}$. Frozen slices of tumor tissues were stained with an uPAR antibody and DAPI. The photograph was obtained on a cryotome Cryostat (Leica, CM 1900, Wetzlar, Germany).

Pharmacokinetics study. To investigate in vivo pharmacokinetics (PK) of RKP and T-RKP micelles, healthy female SD rats were fast for $18 \mathrm{~h}$ before experiment. The rats were randomly divided into three groups $(\mathrm{n}=5)$ and intravenously injected with HSA-PTX plus GEM, RKP and T-RKP micelles (10 mg PTX/kg equiv.) via tail vein, respectively. At $0.25,0.5,1,2,4,8,12$ and $24 \mathrm{~h}$, a blood sample $(0.5 \mathrm{~mL})$ was collected into heparinized tube and centrifuged at $3500 \mathrm{rpm}$ for $10 \mathrm{~min}$. For the determination of PTX concentration, each sample was taken $100 \mu \mathrm{L}$ of supernatant and $10 \mu \mathrm{L}$ of diazepam $(5 \mu \mathrm{g} / \mathrm{mL})$ was added as an internal standard. Then, $100 \mu \mathrm{L}$ of PBS $(\mathrm{pH}=5.5)$ was added to each sample and shaken $24 \mathrm{~h}$ on the air bath at $37^{\circ} \mathrm{C}, 100 \mathrm{rpm}$. Then $100 \mu \mathrm{L}$ of acetonitrile was added to each sample, followed by vortex and centrifugation at $10000 \mathrm{rpm}$ for $5 \mathrm{~min}$ to collect the supernatant. The injection volume was $20 \mu \mathrm{L}$ of each sample for HPLC analysis (Column: Agilent C18, 4.6*250 mm, 5 mm; Detection wavelength: 227 nm; Mobile phase:ACN: $\mathrm{H} 2 \mathrm{O}=60: 40$; Flow rate: $1 \mathrm{~mL} / \mathrm{min})$.

For the determination of GEM concentration, each sample was taken $100 \mu \mathrm{L}$ of supernatant and 10 $\mu \mathrm{L}$ of doxifluridine $(5 \mu \mathrm{g} / \mathrm{mL})$ was added as an internal standard. Then $100 \mu \mathrm{L}$ of PBS $(\mathrm{pH}=5.5)$ was added to each sample and shaken $24 \mathrm{~h}$ on the air bath at $37^{\circ} \mathrm{C}, 100 \mathrm{rpm}$. Then $100 \mu \mathrm{L}$ of ACN was added to each sample, followed by vortex and centrifugation at $10000 \mathrm{rpm}$ for $5 \mathrm{~min}$ to collect the supernatant. The injection volume was $20 \mu \mathrm{L}$ of each sample for HPLC analysis (Column: Agilent C18, 4.6*250 mm, $5 \mathrm{~mm}$; Detection wavelength: $268 \mathrm{~nm}$; Mobile phase:Ammonium acetate 
$(40 \mathrm{mM}): \mathrm{ACN}=97: 3$; Flow rate: $1 \mathrm{~mL} / \mathrm{min})$.

In vitro antitumor efficacy. MTT assay was used to evaluate the in vitro antitumor efficacy. MiaPaCa- 2 and PANC02 cells were seeded in 96 -well plates at a density of $1 \times 10^{3}$ cells/well and routinely maintained until reaching a confluence of $80 \sim 90 \%$. The cells were treated with HSA-PTX, GEM, HSA-PTX plus GEM, RKP and T-RKP at various concentrations for 48h. Afterwards, the medium was removed and cells were washed thrice with PBS before $100 \mu \mathrm{L}$ MTT solution $(0.5$ $\mathrm{mg} / \mathrm{mL}$ ) was added and incubated for $4 \mathrm{~h}$. The MTT was removed and the cells was added with 100 $\mu \mathrm{L}$ DMSO to dissolve the formazan crystal for $15 \mathrm{~min}$. The absorbance of formazan was read at 570 $\mathrm{nm}$ by dual wavelength detection using a Multiskan MK3 microplate reader (Thermo Scientific, Waltham, Massachusetts, USA).

Apoptosis assay. The in vitro apoptosis was evaluated by Annexin-V/PI assay. MiaPaCa-2 or PANC02 cells were seeded in 6-well plate at a density of $1 \times 10^{5}$ per well and cultured for $24 \mathrm{~h}$. The cells were treated with saline, HSA-PTX, GEM, HSA-PTX plus GEM, RKP and T-RKP for 48 hours. Afterwards, the medium was removed and cells were collected and centrifuged at $2000 \mathrm{rpm}$ for 5 min, washed twice with cold PBS, resuspended in binding buffer and stained with Annexin VFITC/PI according to the instructions. Apoptotic cells were evaluated and calculated on a CytoFLEX S (Beckman Coulter, Inc.) or fluoresce microscope (Leica, Wetzlar, Germany).

In vivo antitumor efficacy. 14 days post the implantation with PANC02 xenograft, C57BL/6 mice were randomly divided into six group $(\mathrm{n}=8)$ based on the bioluminescence signal showed by the 
IVIS system that reflects the initial tumor size (the IVIS luminescence intensity is among $8 \sim 12 \times$ $10^{5}$ ). The mice were administrated with saline, HSA-PTX, GEM, HSA-PTX plus GEM, RKP, TRKP with an equal dose of $5 \mathrm{mg} / \mathrm{kg}$ GEM on the 0th, 3rd, 6th, 9th, 12th and 15th day. The body weight and tumor volume of mice was recorded every other day. The growth of the tumor was carefully monitored by the IVIS system.

Ex vivo analysis of tumoral $T$ cells. To study the immune cells in the tumor, tumors were harvested from mice in different groups and stained with anti-CD45-APC (eBioscience, Clone: 30-F11, Catalog: 17-0451-82), anti-CD8-PE (eBioscience, Clone: H35-17.2, Catalog: 12-0083-82), antiCD4-Percp-Cy5.5 (eBioscience, Clone: RM4-5, Catalog: 45-0042-82), anti-CD3-FITC (eBioscience, Clone: 17A2, Catalog: 11-0032-82), anti-CD25-PE-CY7 (eBioscience, Clone: PC61.5, Catalog: 450251-82), anti-FoxP3-PE (eBioscience, Clone: 236A/E7, Catalog: 12-4777-42) antibodies according to the manufacturer's protocols. Briefly, tumor tissues were cut into small pieces and homogenized with PBS (pH 7.4) containing 2\% heat-inactivated fetal bovine serum. The tumor cells were stained with fluorescence-labelled antibodies after the removal of red blood cells (RBC) with the RBC. Cytotoxic $\mathrm{T}$ lymphocytes (CTL) and helper $\mathrm{T}$ cells were marked with $\mathrm{CD} 45^{+} \mathrm{CD} 4{ }^{-} \mathrm{CD} 8^{+}$and $\mathrm{CD} 45^{+} \mathrm{CD} 4{ }^{+} \mathrm{CD} 8$, respectively. Tregs were marked with $\mathrm{CD} 45^{+} \mathrm{CD} 25^{+} \mathrm{CD} 4{ }^{+} \mathrm{FoxP} 3^{+}$. The concentration of IFN- $\gamma$ in tumor was valued by the IFN- $\gamma$ elisa kit according to the protocol.

Confocal microscopy. The tumors were dissected from the mice and snap frozen in OCT medium. Several 5 - $\mu$ m-thick sections were cut using a cryotome and then mounted on slides. Sections were fixed in ice-cold acetone for 10 min prior to rehydration with PBS. After blocking with BSA (3\%), 
sections were stained with primary antibodies overnight at $4^{\circ} \mathrm{C}$. Following the addition of fluorescently labelled secondary antibodies, the slides were analyzed using a confocal microscope (Leica, CM 1900, Wetzlar, Germany).

Tumor metastasis study. Tumor metastasis study was carried out on nude mice at 14 day post implantation with MiaPaCa-2 cells. Saline, HSA-PTX, GEM, HSA-PTX plus GEM, RKP or T-RKP was intravenously administrated into the tumor-bearing mice with an equal dose of $5 \mathrm{mg} / \mathrm{kg}$ GEM on the 0th, 3rd, 6th, 9th, 12th and 15th day. The body weight and tumor volume of mice were recorded every other day. The growth of the tumor was carefully monitored by the IVIS system. The tumors were dissected from the mice after the treatment. The slices were snap frozen in OCT medium for TUNEL staining and immunofluorescence staining of $\alpha$-SMA, IBA1 and VEGF. The tumor, liver, lung, spleen and heart were harvested to evaluate the tumor metastasis foci. The liver sections were stained with H\&E staining, masson staining and CK-19 immunohistochemistry to indicate tumor metastasis site.

Real-Time Quantitative RT-PCR Analysis. For quantitative evaluation of RNA levels of associated proteins, total RNA from the tumor of different groups was isolated using Trizol LS reagent (Invitrogen, USA) according to the manufacturer's instructions. The RT-PCR analysis was performed by Wuhan Servicebio Co. Ltd. Primer sequence: GAPDH-F: 5' CATGAGAAGTATGACAACAGCCT; GAPDH-R: 5' AGTCCTTCCACGATACCAAAGT; MENA11a-F: 5' CCAACCAGAAAACCTTGGG; MENA11a-R: 5' TGCTTCAGCCTCTCATAG TCA; Mena ${ }^{I N V}$-F: 5' GATTCAAGACCATCAGGTTGTG; $M e n a^{I N V}$-R: 5' TACATCGCAAATTA 
GTGCTGTC; PanMena-F: 5, AGgCtGAagCAGGaCATTT; PanMena-R: 5' TGCTCAGTTCCTGCCTGAT.

Statistical analysis. All results represent mean \pm s.d. as indicated. Data were analysed using Student's t-test or One-way analysis of variance (ANOVA), except where otherwise noted. Tumour volumes were compared using the Kruskal-Wallis test followed by the Mann-Whitney U test. All statistical analyses were performed using the Prism software package (PRISM 5.0; GraphPad Software, USA, 2007). Differences between groups were considered statistically significant when two-sided $\mathrm{P}<0.05$. 


\section{Supplemented Figures}

A

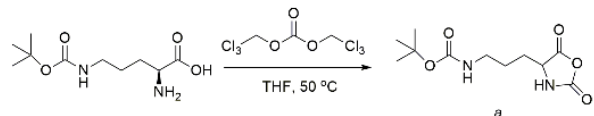

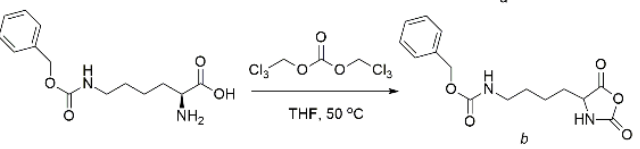
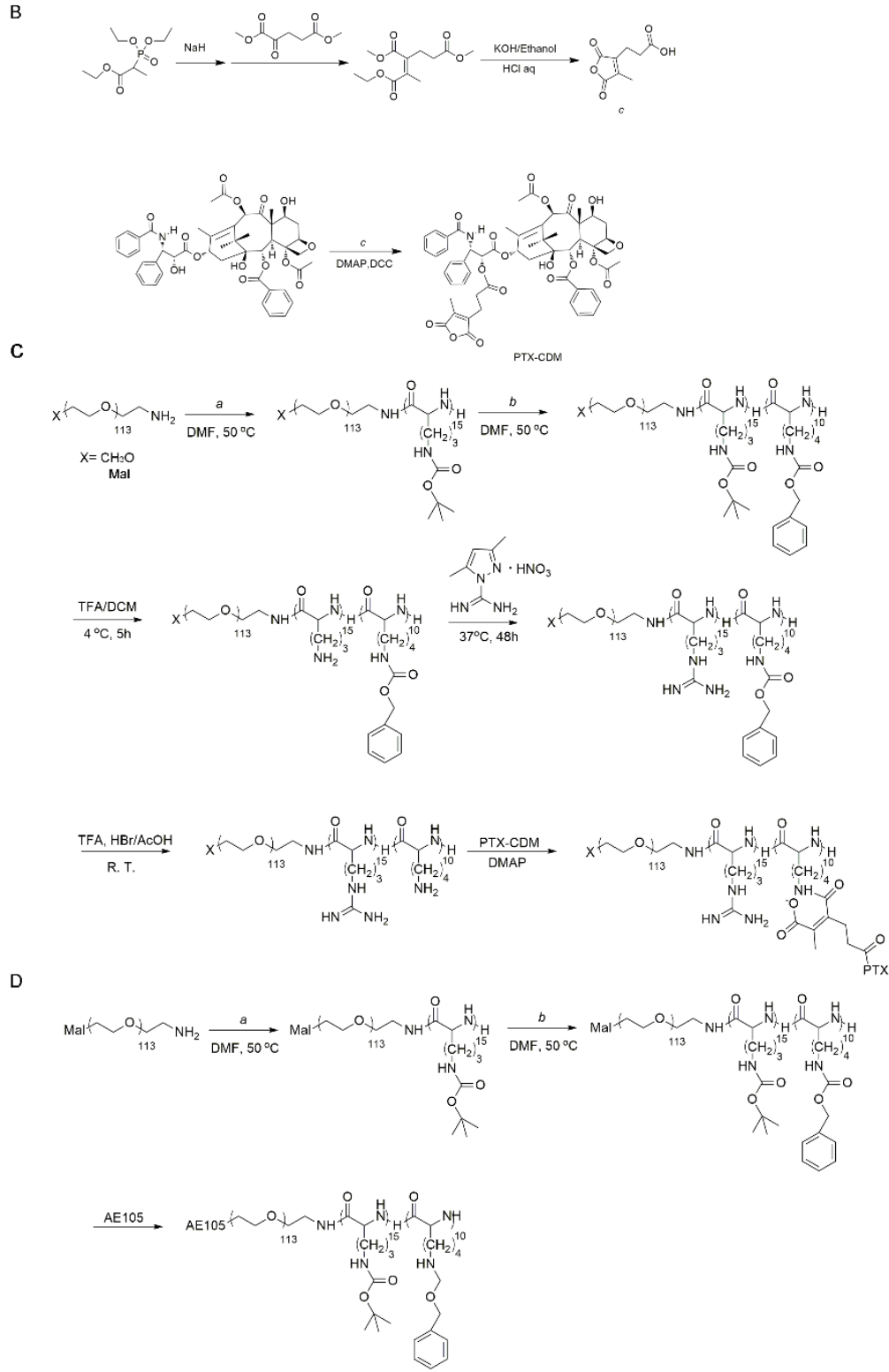

Figure S1. Synthesis route of AE105-PEG-pArg 15 -pLys $10-C D M-P T X$ polymer. (A) The synthesis of Orn-(Boc)-NCA (upper) and Lys-(CBZ)-NCA (down). (B) The synthesis of CDM (upper) and

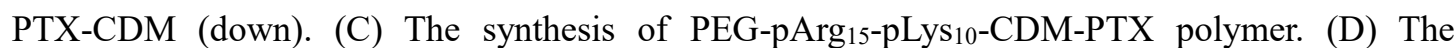
synthesis of AE105-PEG-pOrn(Boc) ${ }_{15}$-pLys(CBZ) 10 . 

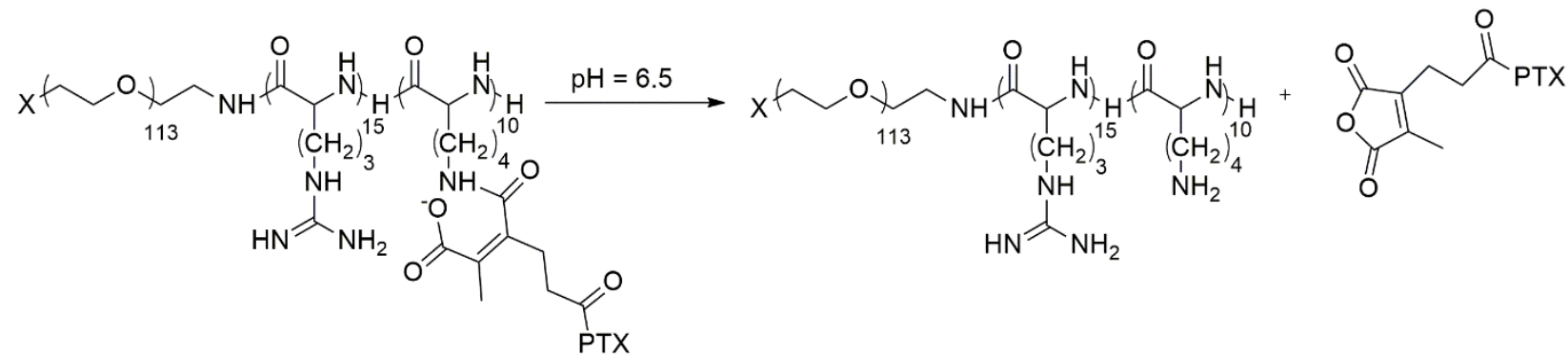

Figure S2. The $\mathrm{pH}$ sensitive mechanism of CDM.

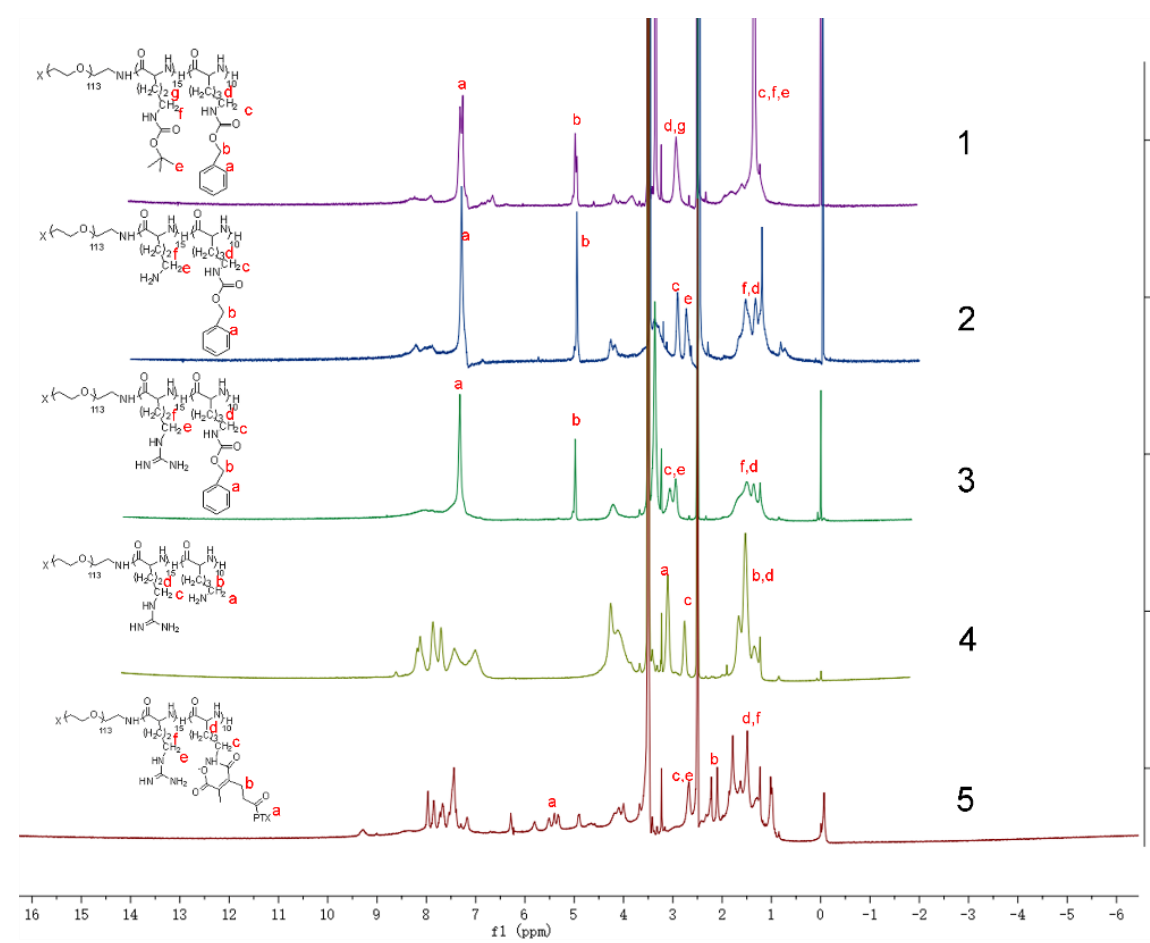

Figure S3. ${ }^{1} \mathrm{H}$ NMR spectrum of (1) PEG-pOrn(Boc)-pLys(Cbz), (2) PEG-pOrn-pLys(Cbz), (3)

PEG-pArg-pLys(Cbz), (4) PEG-pArg-pLys and (5) PEG-pArg-pLys-PTX. 


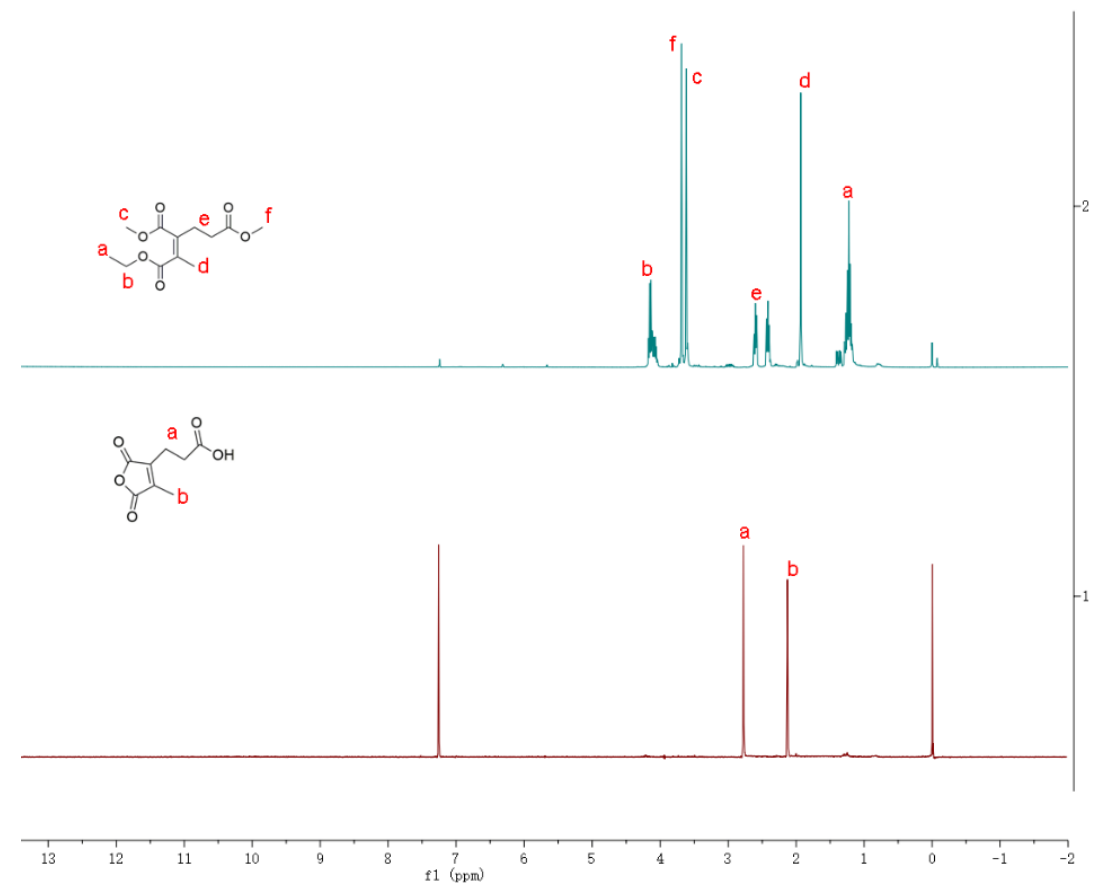

Figure S4. ${ }^{1} \mathrm{H}$ NMR spectrum of 3-pentene-1,3,4-tricarboxylic acid-4-ethyl-1,3-dimethyl ester (upper) and 2-propionic-3-methylmaleic anhydride (CDM, down).

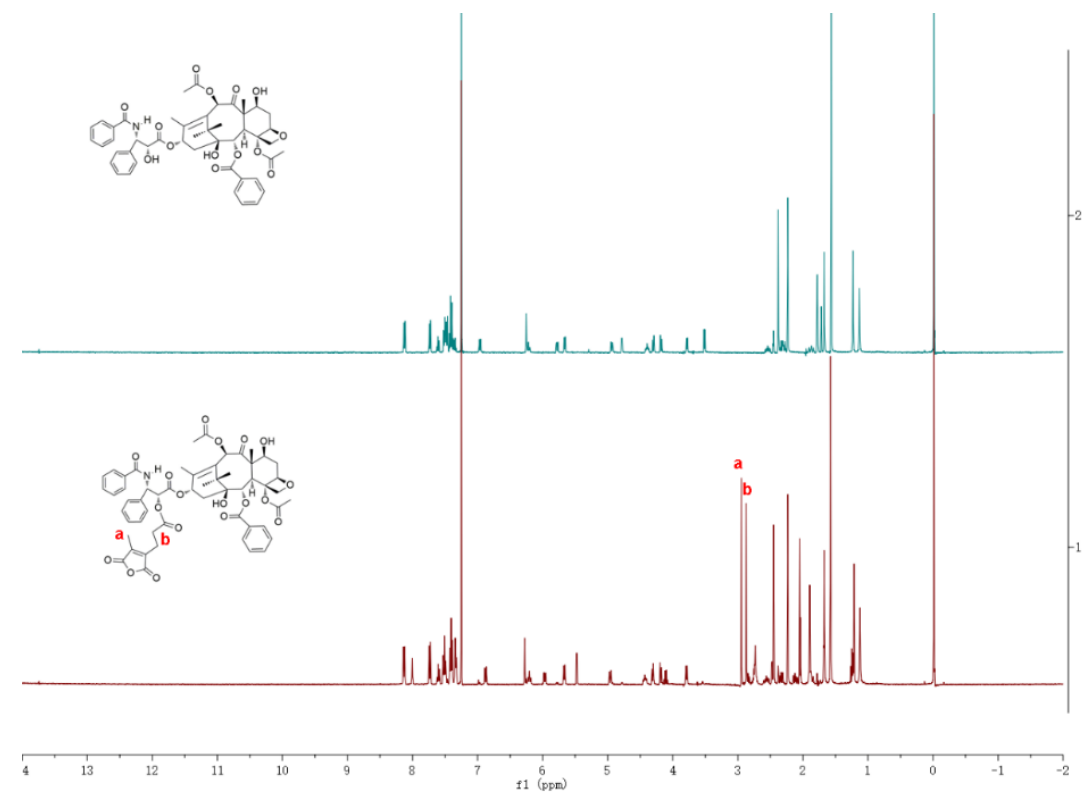

Figure S5. ${ }^{1} \mathrm{H}$ NMR spectrum of paclitaxel (upper) and paclitaxel-CDM (down). 


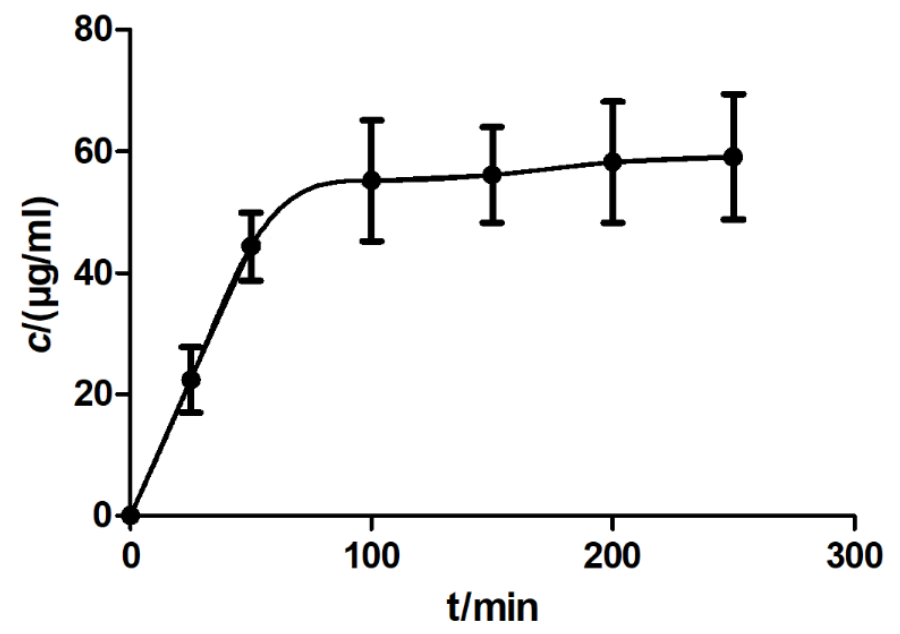

Figure S6. Concentration of p-GEM in PANC02 cells at different times.

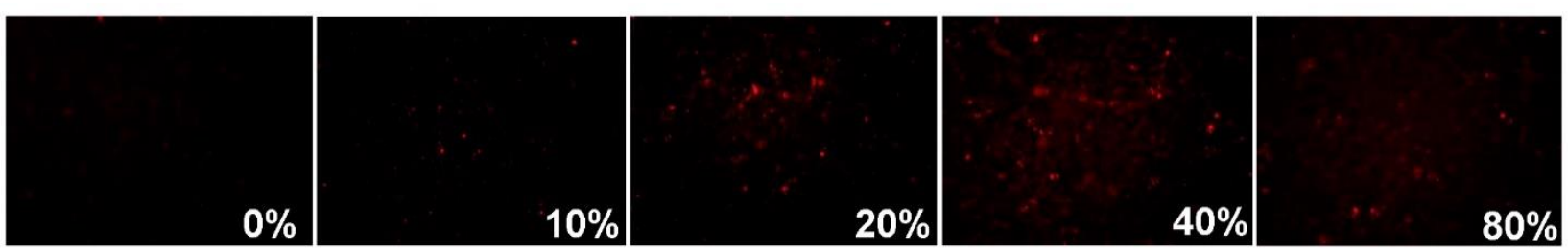

Figure S7. In vitro targeting effect of T-RKP in different AE105 modification rate. Red: T-RKP.

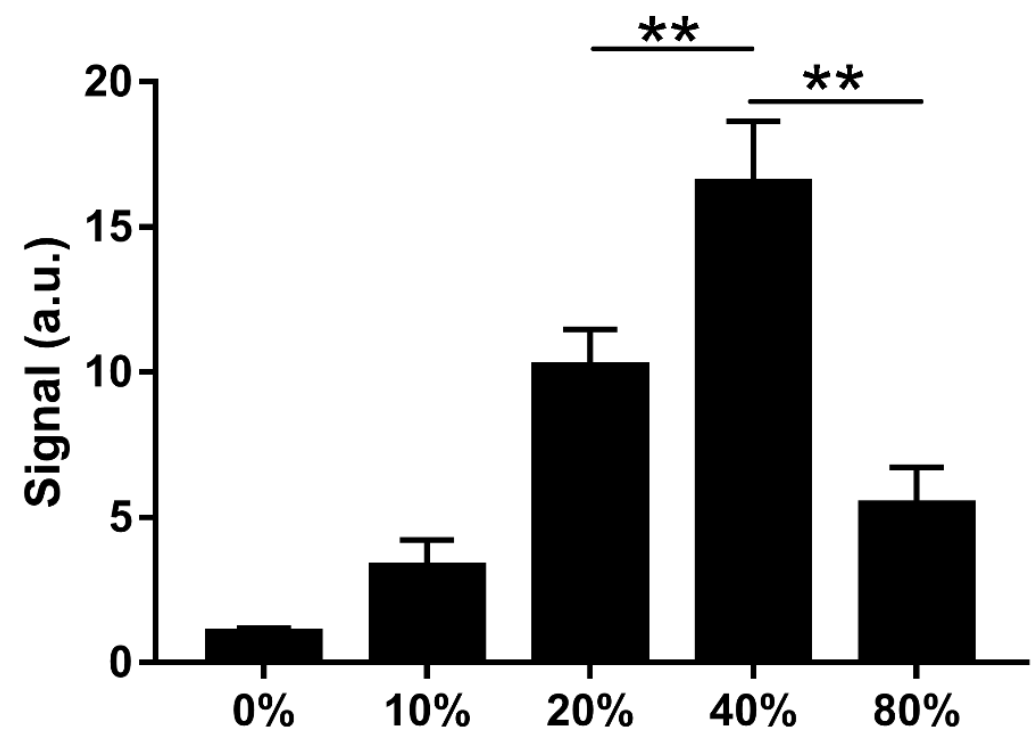

Figure S8. Statistic results of the targeting effect of T-RKP in different AE105 modification rates. Data represent means \pm s.d. $(\mathrm{n}=10) .{ }^{* *} \mathrm{P}<0.01$. 


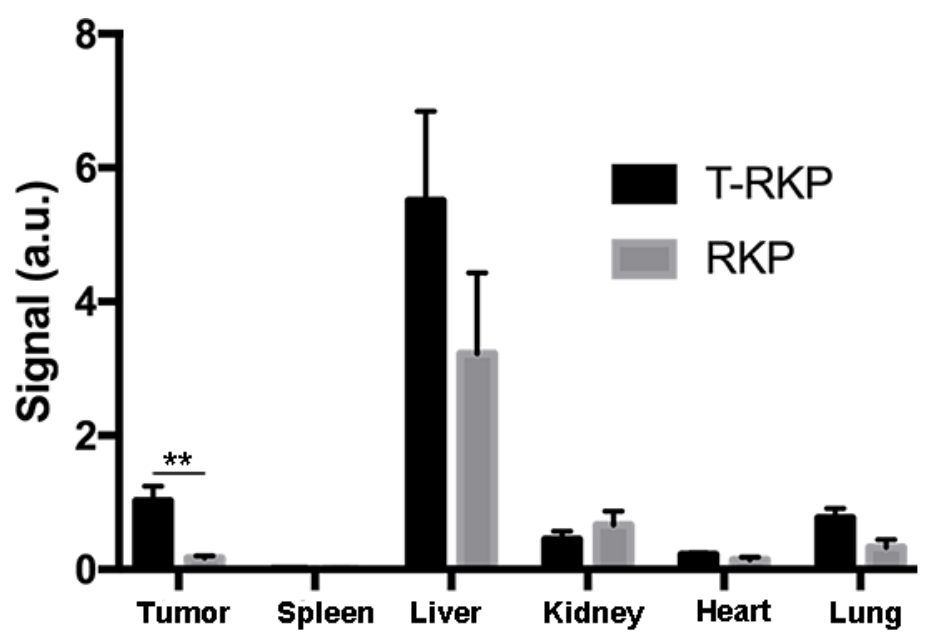

Figure S9. Statistic results of T-RKP or RKP signal in different organs. Data represent means \pm s.d. $(\mathrm{n}=6) .{ }^{* *} \mathrm{P}<0.01$.
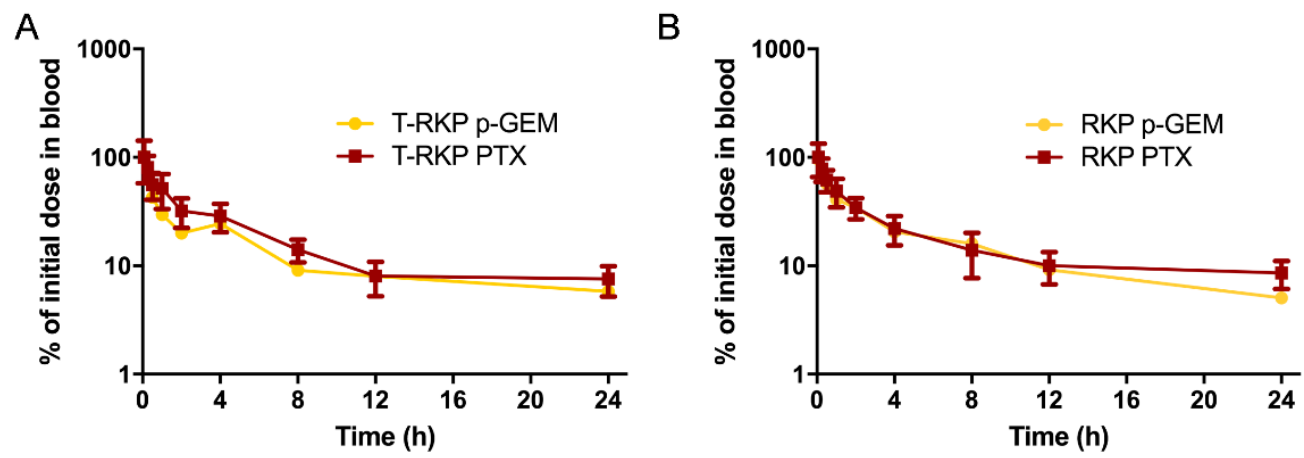

Figure S10. (A) Pharmacokinetics profile of p-GEM and PTX in T-RKP treated groups. (B) Pharmacokinetics profile of p-GEM and PTX in RKP treated groups. n.s. represents nonsignificance. 


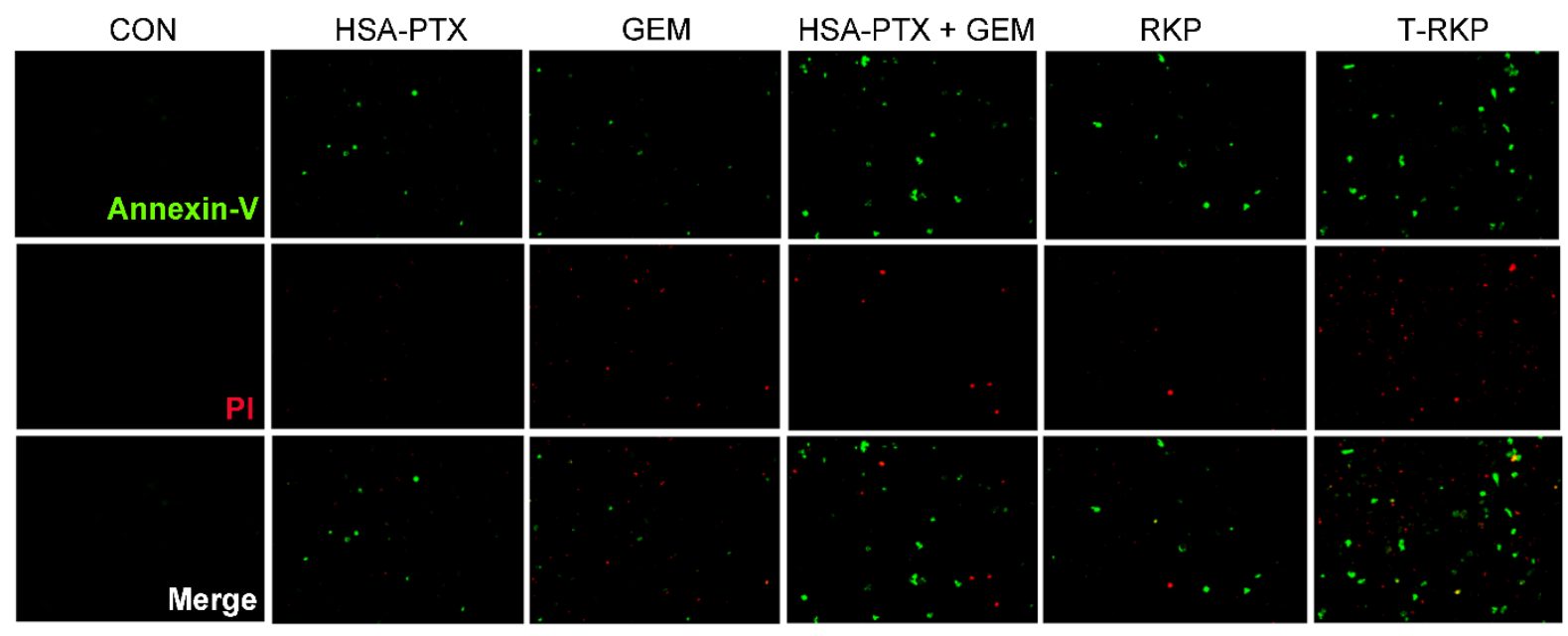

Figure S11. Annexin-V/PI assay after different treatments in MiaPaCa-2 cell. The green signal indicates the annexin- $\mathrm{V}$ signal, and the red signal indicates the PI signal. Original magnification = 200. Data represent the means \pm s.d. $(n=6)$.

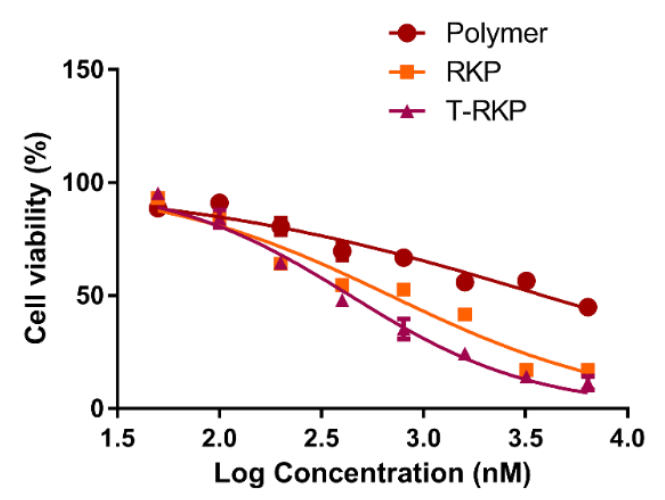

Figure S12. MTT assays in MiaPaCa-2 cells (different polymer concentration) in the polymer, RKP and T-RKP treated group.

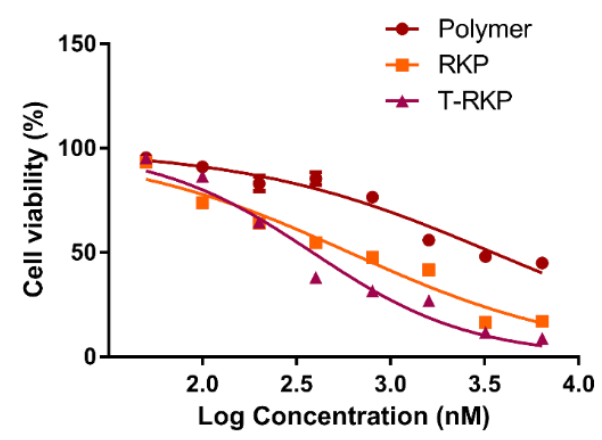

Figure S13. MTT assays in PANC02 cells (different polymer concentrations) in the polymer, RKP and T-RKP treated group. 


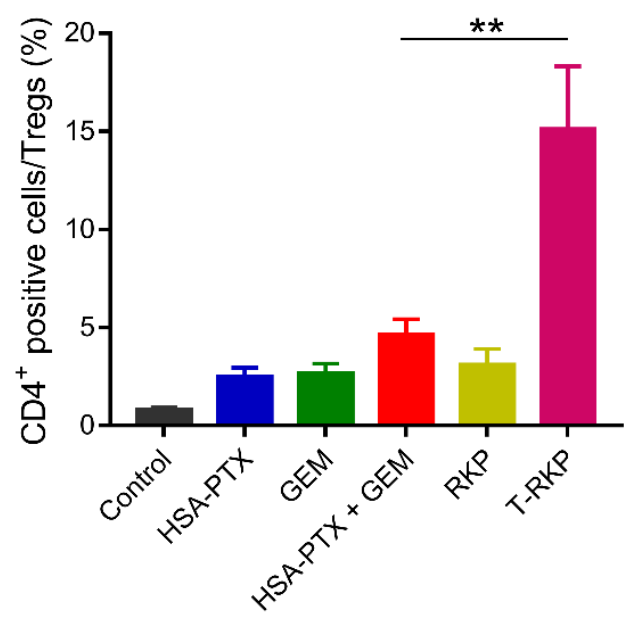

Figure S14. The ratios of CD4 positive cells in different groups with Tregs. Data represent means \pm s.d. $(\mathrm{n}=6) .{ }^{* *} \mathrm{P}<0.01$.

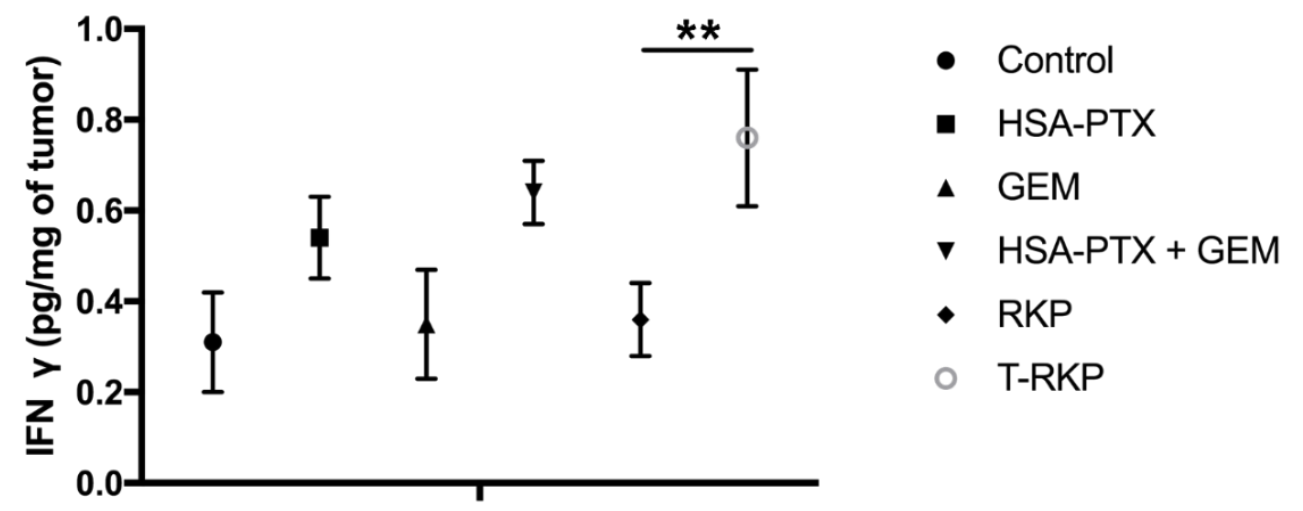

Figure S15. Expression of IFN- $\gamma$ in tumor after different treatments. Data represent means \pm s.d. $(\mathrm{n}=6) .{ }^{*} \mathrm{P}<0.05,{ }^{* *} \mathrm{P}<0.01$.

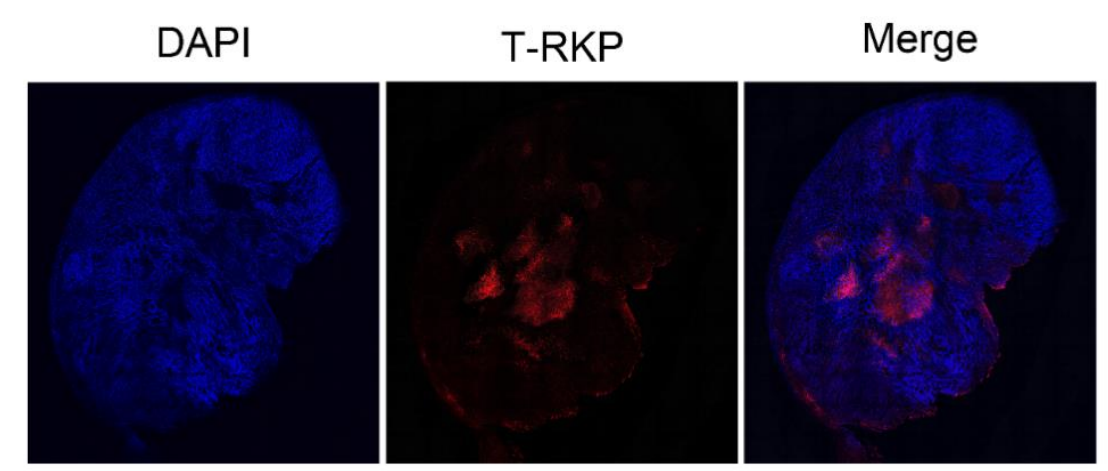

Figure S16. The distribution of T-RKP in pancreatic bearing mice. Red: T-RKP. Blue: DAPI. 


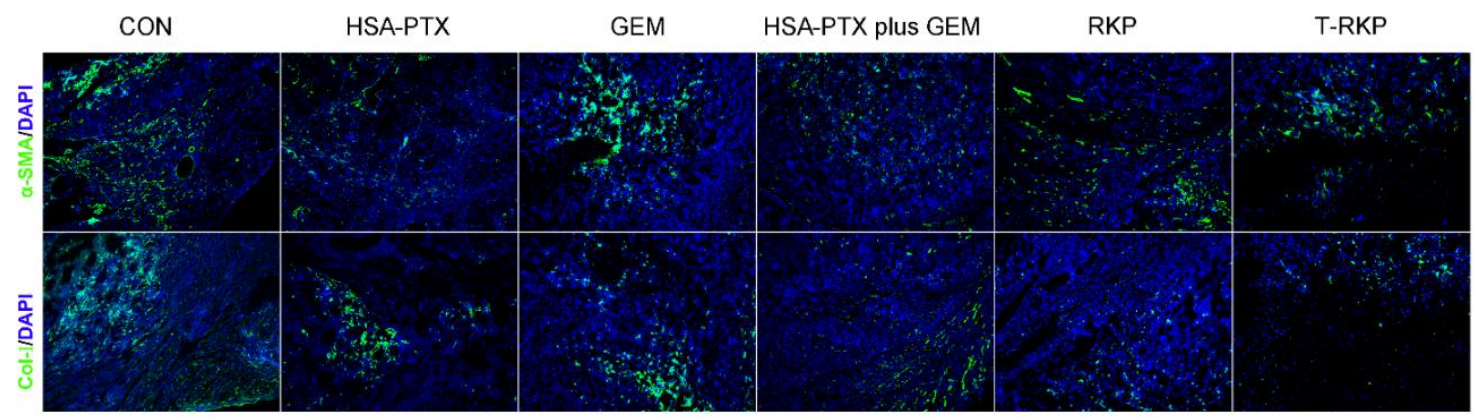

Figure S17. Tumor slices were immunostained for $\alpha$-SMA (green, upper) and Col-I (green, down) and DAPI (blue) for nuclear staining. Original magnification $=200$.

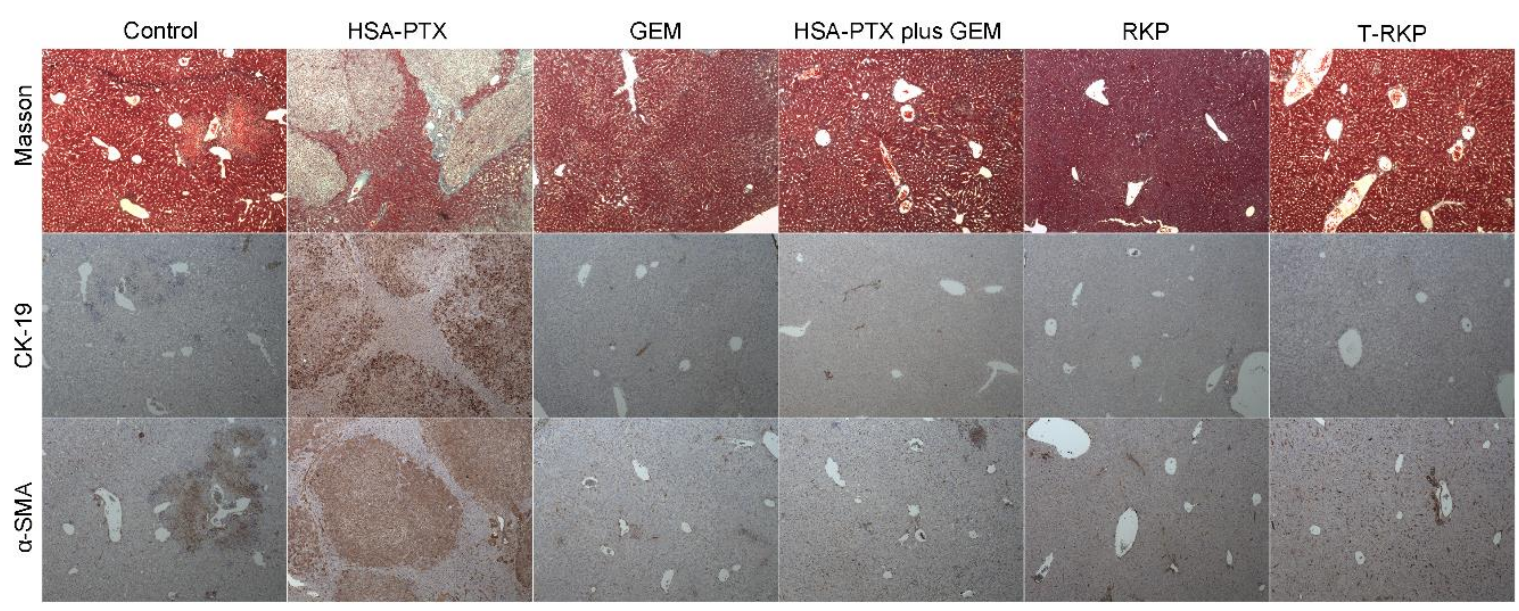

Figure S18. Liver were stained for masson staining (upper), $\alpha$-SMA staining (middle) and CK-19 (down) after different treatments. 


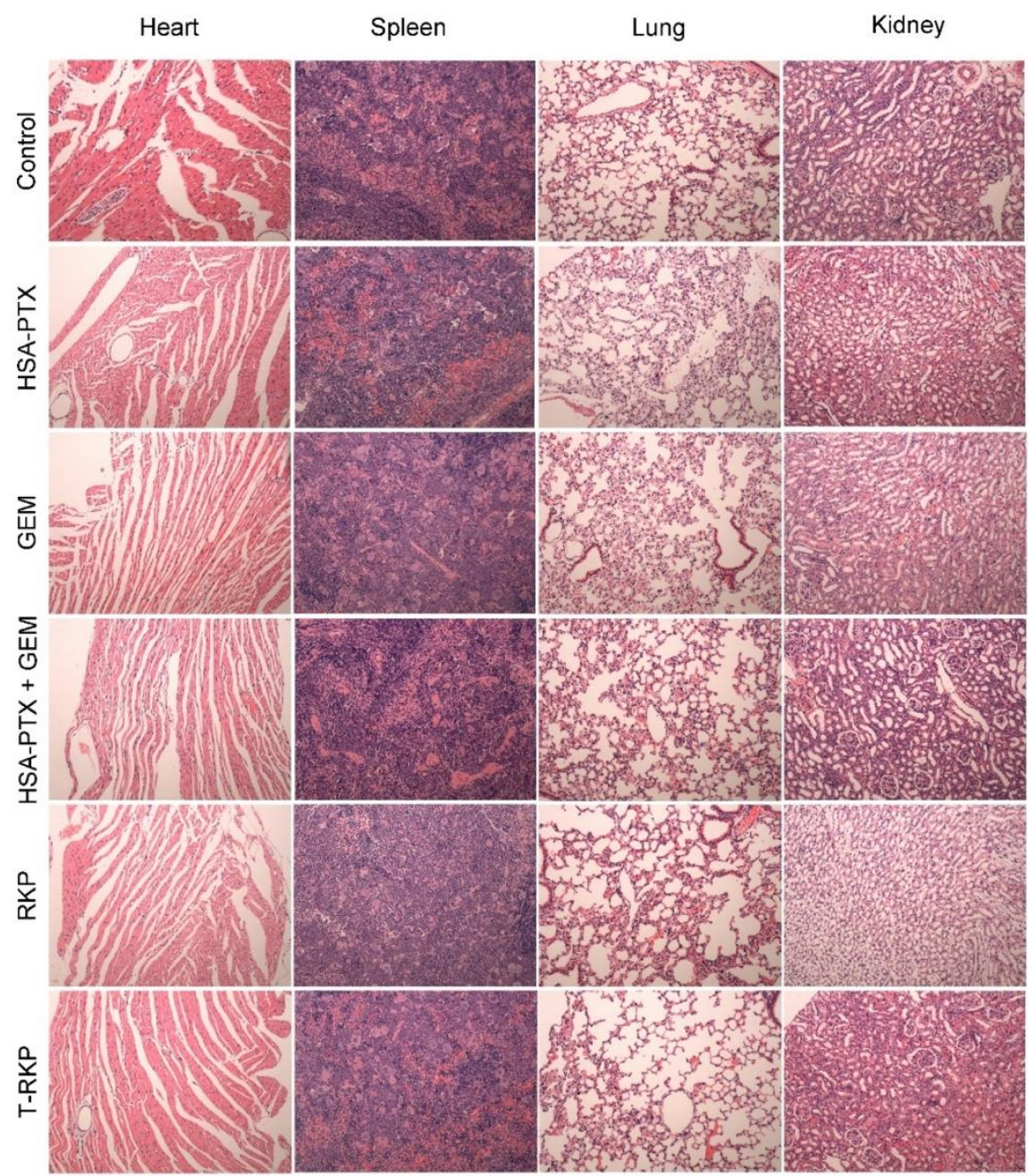

Figure S19. H\&E staining images of the heart, spleen, lung and kidney after one-month treatment. 


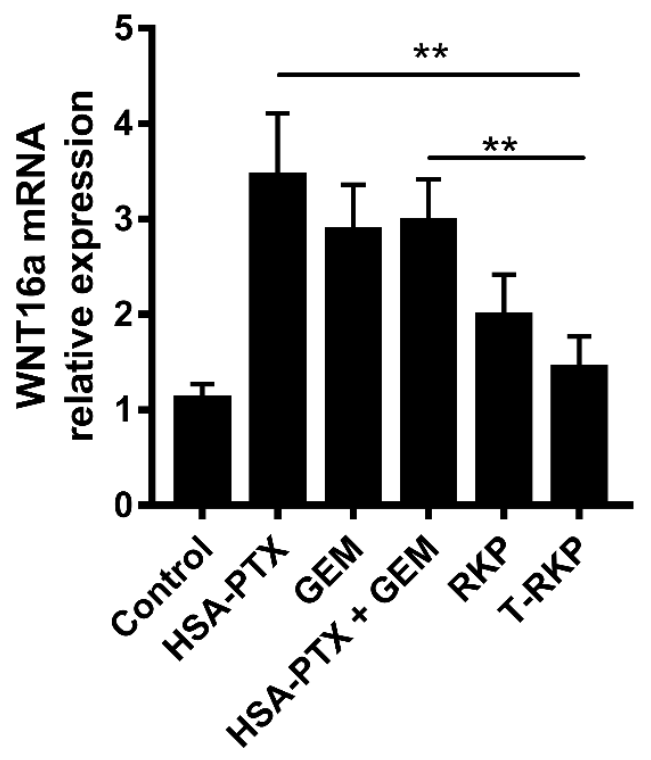

Figure S20. The gene expression of WNT16a in the tumor outer tissue after different treatments (Saline, HSA-PTX, GEM, HSA-PTX + GEM, RKP and T-RKP).

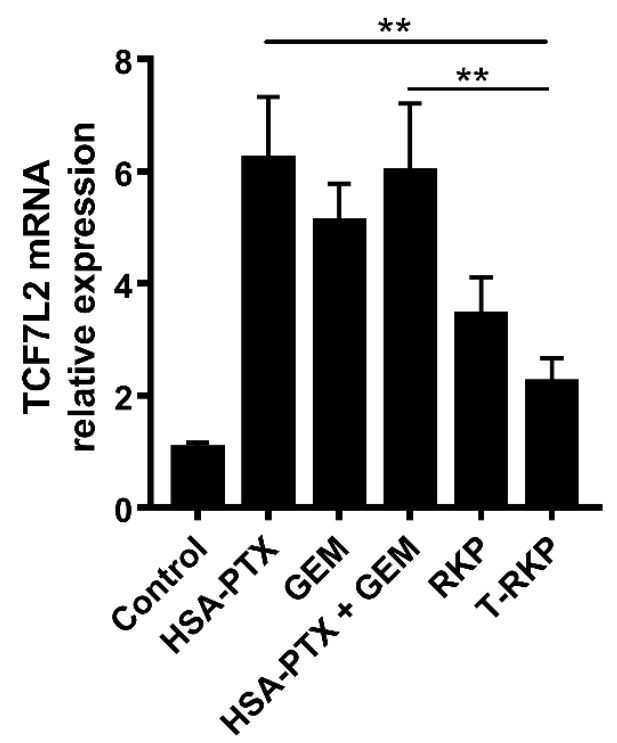

Figure S21. The gene expression of TCF7L2 in the tumor outer tissue after different treatments (Saline, HSA-PTX, GEM, HSA-PTX + GEM, RKP and T-RKP). 


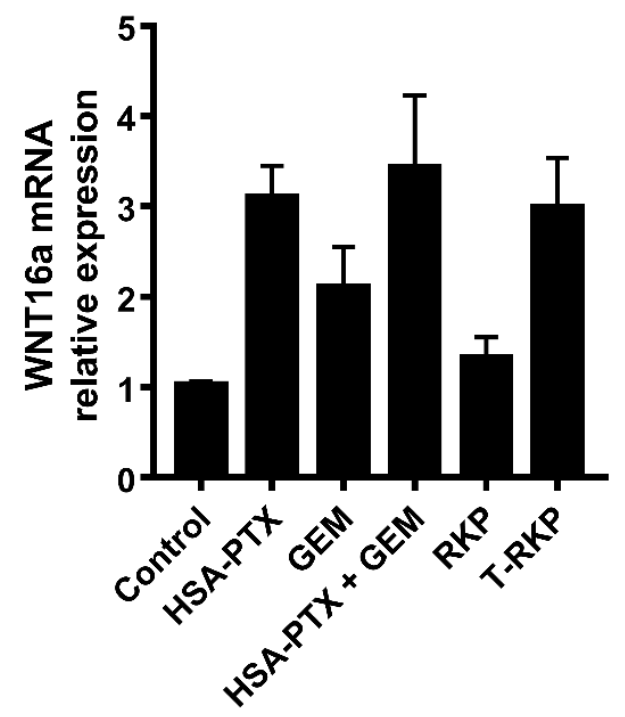

Figure S22. The gene expression of WNT16a in the tumor core after different treatments (Saline, HSA-PTX, GEM, HSA-PTX + GEM, RKP and T-RKP).

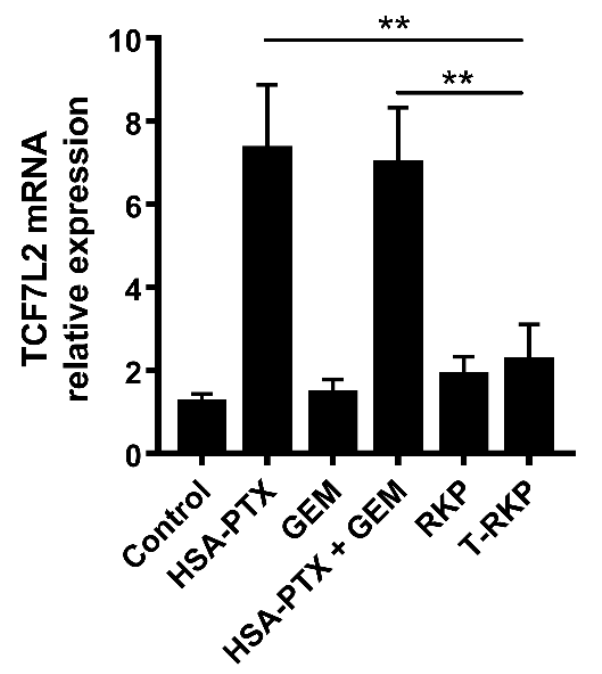

Figure S23. The gene expression of TCF7L2 in the tumor core after different treatments (Saline, HSA-PTX, GEM, HSA-PTX + GEM, RKP and T-RKP). 
Table S1. Summary of micelle properties.

\begin{tabular}{cccccc}
\hline Polymeric micelles & Size $[\boldsymbol{d}, \mathbf{n m}]$ & PDI & Zeta potential $[\mathbf{m V}]$ & p-DL\% & g-DL\% $^{\text {a) }}$ \\
\hline T-RKP & $65.5 \pm 4.3$ & $0.08 \pm 0.01$ & $2.31 \pm 0.28$ & $26.3 \pm 5.3 \%$ & $8.6 \pm 0.3 \%$ \\
RKP & $70.5 \pm 3.2$ & $0.06 \pm 0.02$ & $2.21 \pm 0.33$ & $28.8 \pm 4.7 \%$ & $7.7 \pm 0.7 \%$ \\
\hline
\end{tabular}

${ }^{a)}$ Drug loading (DL\%): ratio of encapsulated drug to the total mass of micelles. (p-DL: paclitaxel loading, g-DL: phosphorylated gemcitabine loading)

Table S2. Pharmacokinetic parameters of different PTX formulations in SD rats at a dose of $15 \mathrm{mg} / \mathrm{kg}$ PTX. Data are presented as mean \pm SD $(n=6)$.

\begin{tabular}{lccc}
\hline & HSA-PTX & RKP & T-RKP \\
\hline $\mathrm{AUC}_{0-\infty}(\mathrm{mg} / \mathrm{L} * \mathrm{~h})$ & $187.334 \pm 76.674$ & $258.125 \pm 118.663$ & $227.334 \pm 99.998$ \\
$\mathrm{MRT}(\mathrm{h})$ & $11.357 \pm 3.225$ & $14.896 \pm 4.485$ & $13.449 \pm 3.217$ \\
$\mathrm{Cl}(\mathrm{L} / \mathrm{h})$ & $0.055 \pm 0.019$ & $0.046 \pm 0.014$ & $0.049 \pm 0.017$ \\
$\mathrm{t}_{1 / 2}(\mathrm{~h})$ & $8.593 \pm 3.241$ & $10.354 \pm 3.892$ & $10.115 \pm 4.131$ \\
\hline
\end{tabular}

Table S3. Pharmacokinetic parameters of different GEM or p-GEM formulations in SD rats at a dose of $5 \mathrm{mg} / \mathrm{kg}$ GEM or $\mathrm{p}-\mathrm{GEM}$. Data are presented as mean $\pm \mathrm{SD}(\mathrm{n}=6)$.

\begin{tabular}{lccc}
\hline & Gem & RKP & T-RKP \\
\hline $\mathrm{AUC}_{0-\infty}(\mathrm{mg} / \mathrm{L} * \mathrm{~h})$ & $9.114 \pm 2.576$ & $45.339 \pm 18.327$ & $41.269 \pm 13.431$ \\
$\mathrm{MRT}(\mathrm{h})$ & $2.975 \pm 0.764$ & $8.332 \pm 3.634$ & $7.583 \pm 2.216$ \\
$\mathrm{Cl}(\mathrm{L} / \mathrm{h})$ & $0.196 \pm 0.058$ & $0.073 \pm 0.025$ & $0.088 \pm 0.031$ \\
$\mathrm{t}_{1 / 2}(\mathrm{~h})$ & $1.833 \pm 0.441$ & $5.132 \pm 1.116$ & $4.898 \pm 1.433$ \\
\hline
\end{tabular}

Table S4. $\mathrm{IC}_{50}$ of different formulations based on PTX concentrations in PANC02 and MiaPaCa-2 cells.

\begin{tabular}{ccccc}
\hline IC $_{50}(\mathbf{n M})$ & PTX-HSA & $\begin{array}{c}\text { PTX-HSA plus } \\
\text { GEM }\end{array}$ & RKP & T-RKP \\
\hline PANC02 & 199.7 & 227.6 & 466.3 & 142.3 \\
$\mathrm{MiaPaCa}-2$ & 304.2 & 288.5 & 423.5 & 178.6 \\
\hline
\end{tabular}

Table S5. $\mathrm{IC}_{50}$ of different formulations based on GEM concentrations in PANC02 and MiaPaCa-2 cells.

\begin{tabular}{ccccc}
\hline IC $_{\mathbf{5 0}}(\mathbf{n M})$ & PTX-HSA & $\begin{array}{c}\text { PTX-HSA plus } \\
\text { GEM }\end{array}$ & RKP & T-RKP \\
\hline PANC02 & 514.3 & 163.4 & 246.5 & 93.2 \\
$\mathrm{MiaPaCa}-2$ & 333.5 & 145.3 & 311.2 & 129.6 \\
\hline
\end{tabular}

References: 
(1) Wang, S.; Gong, G.; Su, H.; Liu, W.; Wang, Z.; Li, L. Polym Chem. 2014, 5, 4871-4.

(2) Wang, W.; Huang, Y.; Zhao, S.; Shao, T.; Cheng, Y. Chem Commun. 2013, 49, 2234-36.

(3) Barrett, SE.; Burke, RS.; Abrams, MT.; Bason, C.; Busuek, M.; Carlini, E.; Carr, B. A.; Crocker, LS.; Fan, H.; Garbaccio, RM. J Control Release. 2014, 183, 124-37.

(4) Guo, Y.; Zhang, Y.; Li, J.; Zhang, Y.; Lu, Y.; Jiang, X.; He, X.; Ma, H.; An, S.; Jiang, C. Acs Appl Mater Interfaces. 2015, 7, 5444-53. 